\title{
Actuarial valuations to monitor defined benefit pension funding
}

\author{
Christopher D. O'Brien \\ Correspondence to: Christopher D. O’Brien, 64 Hillside Road, Beeston, Nottingham NG9 3AY \\ E-mail: chris.obrien.abc@gmail.com
}

\begin{abstract}
This paper is motivated by The Pensions Regulator (TPR)'s review of its Code of Practice on funding for defined benefit schemes and aims to suggest how trustees and regulators should monitor the extent to which scheme assets are adequate to cover liabilities. It concludes that current practice is inadequate and needs to change.

A review is carried out of papers on not only this subject but also (to collect ideas rather than automatically apply them to pensions solvency valuations) pensions and insurance accounting and regulation.

Current practice is "scheme-specific funding" which permits discretion on choice of discount rates and other assumptions; the paper is concerned that this can lead to bias, and that trends in a scheme's solvency can be obscured by changing assumptions. This also leads to the funding ratio communicated to scheme members having little meaning.

The paper suggests that regulators should require a valuation that is based on sound principles, objective, fair, neutral, transparent and feasible. A prescribed methodology would replace discretion.

It concludes that the benefits to be valued are those arising on discontinuance of the scheme, without allowing for future salary-related benefit increases, which are felt to no longer be a constructive obligation of employers.

The valuation should, it is suggested, use market values of assets, which is largely current practice.

Liabilities should reflect the trustees fulfilling their liabilities, rather than transferring them to an insurer (which may introduce artificialities).

The discount rate should follow the "matching" approach, being a market-consistent risk-free rate: this is consistent with several papers to the profession in recent years. It avoids the problems of the "budgeting" approach, where the discount rate is based on the expected return on assets - this can be used to help set contribution levels but is not suitable for determining the value of liabilities, which depends on salary, service, longevity, etc and (very largely) not on the assets held. In principle, the liability value can be adjusted for illiquidity. Credit risk of the employer should not be allowed for.

Liabilities should reflect the (probability-weighted) expected value of future cash flows and should not be increased by prudent margins or risk margins (which would lead to a non-neutral figure). Risk disclosures are needed to understand and manage risks.

The resulting funding ratio is a consistent measure, to be disclosed to members, which can be used to manage the scheme, and by regulators as the basis for requiring action. Scheme-specific management using data such as the employer covenant means that immediate action to ensure $100 \%$ solvency on the proposed basis would not necessarily be appropriate.

The author encourages the profession to advise TPR on the above lines.
\end{abstract}

Keywords: Defined benefit schemes; Valuation methods; Funding; Discount rates; Pension regulation

\section{Introduction}

Employers typically fund pension liabilities in advance: funding improves benefit security for scheme members, can help corporate cash management, may reflect tax incentives and is a response

(c) Institute and Faculty of Actuaries 2020. This is an Open Access article, distributed under the terms of the Creative Commons Attribution licence (http://creativecommons.org/licenses/by/4.0/), which permits unrestricted re-use, distribution, and reproduction in any medium, provided the original work is properly cited. 
to regulation (Cowling et al., 2005). However, employers may prefer to delay funding, to give them flexibility in running the business and avoid the possibility of a surplus in the fund having to be used to enhance members' benefits (the "stranded surplus" problem). Indeed, in the difficult financial times of the 1970s, the advantages of funding were questioned (Turnbull, 2017).

Regulation can help ensure that the tension in funding is resolved satisfactorily, bearing in mind that employers are usually in a stronger negotiating position than members, and that pension funding is a complex subject that members, and also employers, may fail to understand. In the UK, the Department of Work and Pensions (DWP) and The Pensions Regulator (TPR) have responsibility for the regulation and acknowledge the different perspectives of employers and members: "The UK DB [defined benefit] funding regime is not designed to eliminate all risk to members' benefits. Rather it seeks to strike a reasonable balance between the demands on the employer and the security of members' benefits, recognising that a strong, sustainable sponsoring employer is the best protection for a DB scheme" (DWP, 2017).

Following some high-profile scheme failures, the DWP (2017) consulted on several issues concerning DB schemes. As part of its response it asked TPR to review and amend the Code of Practice it had issued (TPR, 2014) on funding for DB schemes (DWP, 2018b). This paper has been prepared to contribute to the review process.

The Pension Schemes Bill (2020), as introduced to the House of Lords, proposed financial penalties for conduct risking accrued benefits. The suggestions in this paper may help determine whether such conduct has taken place.

The aim of the paper is to develop a benchmark valuation to illustrate the solvency of DB schemes, in the sense of the extent to which the assets are adequate for the liabilities. This is intended to be fair between the parties involved and to provide a clear and consistent measure that can serve as the basis, in conjunction with other information as appropriate, for actions in connection with the scheme. In addition to informing trustees and firms, it would also be the focus of scheme solvency information presented to scheme members.

It is not intended that regulators require that schemes be funded at $100 \%$ in accordance with the benchmark valuation: the circumstances of the scheme and the sponsoring firm are important in determining the response to the valuation outcome ("scheme-specific management"). Nevertheless, the intention is that the benchmark valuation will be helpful to pensions regulators in providing a clear and consistent measure of scheme solvency. The benchmark valuation can also be used to set a funding target. It should also be mentioned upfront that using a comparison of fund assets and the cost of a buyout from an insurer is not necessarily to be regarded as the benchmark valuation for solvency, although it is one of the options considered.

The methodology adopted is to examine alternative approaches to valuation, considering not only actuarial literature and current practice in DB pension valuations but also valuations carried out for accounting and regulatory purposes in both pensions and insurance. Reference is made to the valuation carried out for the firm's accounts, which is subject to some specific rules, notably IAS 19, the standard issued by the International Accounting Standards Board (IASB) for retirement benefits (compulsory for listed companies in the EU), to which it will be useful to refer at various points. The limitations of other approaches are taken into account, for example, valuations for insurance regulation have rather different purposes. However, they may have features that are useful for the present research.

Managing a scheme also involves, inter alia, attention to cash flows; this has been of increased importance and attention as schemes have closed (see, e.g. McAleer \& Wardle, 2018). This paper's focus on balance sheet valuations should not be taken as denying the importance of cash flows; rather, it emanates from the current regulatory focus on funding.

Section 2 reviews current practice and finds it wanting; it derives from scheme-specific funding, which is considered in section 3 . While funding will reflect the specific circumstances of employers and schemes, it is argued that valuations should follow general principles, avoiding what are argued to be the distortions that arise at present. It is valuable to have a benchmark to assess 
the build-up of the fund in comparison with the scheme's obligations, and section 4 suggests what the characteristics of such a benchmark should be. Subsequent sections examine how the benchmark valuation should be carried out, considering the benefits to be valued (section 5), the valuation of assets (section 6) and of liabilities (section 7). Section 8 considers the process for calculating the contributions to a scheme; section 9 reflects on the findings and discusses the way forward; and section 10 concludes.

\section{Current Practice}

In accordance with the Pensions Act 2004, a DB scheme is subject to a requirement ("the statutory funding objective") that it must have sufficient and appropriate assets to cover its technical provisions, which are an actuarial calculation of the scheme liabilities. The trustees have to prepare a statement of funding principles, setting out their policy for achieving the statutory funding objective and must obtain an actuarial valuation of the scheme's assets and technical provisions, typically every 3 years, with a less detailed actuarial report in the intervening years. If, at the time of an actuarial valuation, the statutory funding objective is not met, the trustees have to prepare (or revise) a recovery plan that sets out the steps to be taken to meet the objective and the period within which it is to be achieved.

The Act requires that, before making any decision on the methods and assumptions to be used in calculating the scheme's technical provisions, the trustees must obtain the advice of an actuary, and the trustees must obtain the agreement of the employer to their decision. The technical provisions use an accrued benefits funding method. The regulations on funding ${ }^{1}$ require

- the economic and actuarial assumptions must be chosen prudently, taking account, if applicable, of an appropriate margin for adverse deviation;

- the rates of interest used to discount future payments of benefits must be chosen prudently, taking into account either or both

(i) the yield on assets held by the scheme to fund future benefits and the anticipated future investment returns, and

(ii) the market redemption yields on government or other high-quality bonds;

- the mortality tables used and the demographic assumptions made must be based on prudent principles, having regard to the main characteristics of the members as a group and expected changes in the risks to the scheme.

The actuarial valuation must also include the actuary's estimate of the solvency of the scheme where, in accordance with the funding regulations, the liabilities are calculated as the cost of buying annuities from an insurance company.

There are some helpful comments about the choice of assumptions underlying the technical provisions in TPR's (2014) Code of Practice. This indicates that trustees should use individual assumptions the prudence of which is consistent with the overall level of prudence required for the technical provisions. The assumptions should be evidence-based. Trustees should have good reasons if they do not follow the advice of the actuary. Since the Act requires the actuary to certify that the technical provisions are calculated in accordance with the regulations, the trustees have to recognise that the actuary would need to report to the regulator if they instruct the actuary to use an approach that the actuary considers inconsistent with the Act.

The typical practice in the UK is that schemes use a discount rate that is a prudent estimate of the expected rate of return on the assets in the fund. Where the assets include equities, this return includes the equity risk premium. The evidence from TPR (2019) for scheme valuations in 2016/ 17 is that where equities and other "return-seeking assets" were less than $20 \%$ of the fund, the

${ }^{1}$ The Occupational Pension Schemes (Scheme Funding) Regulations 2005, SI 2005/3377. 
discount rate averaged $2.176 \%$, compared with $3.098 \%$ where return-seeking assets were $80 \%$ or more. This is consistent with valuations being based on the (prudent) expected return.

The regulations on disclosure ${ }^{2}$ require the trustees to issue a summary funding statement to members with $\mathrm{DB}$ benefits following each actuarial valuation and report. This must include, inter alia:

- a summary that explains the extent to which the assets of the scheme are adequate to cover its technical provisions;

- an explanation of any change in the funding position of the scheme since the date of the previous summary funding statement;

- the actuary's estimate of solvency contained in the last actuarial valuation; and

- a summary of any recovery plan.

This highlights the importance of actuaries' work: it is not only a technical exercise for the trustees but also forms the basis of the communication to members. As Dyson \& Exley (1995) pointed out, the widespread dissemination of valuation results leads to an issue for the public perception of the actuarial profession.

In practice, it is common for trustees to emphasise that the solvency position is provided because the regulations require it and that the trustees have no intention of discontinuing the scheme. ${ }^{3}$ The implication is that members focus on the funding ratio expressed as the ratio of assets to technical provisions. It is reasonable to think that they regard the ratio as an indicator of the financial strength of the scheme.

\section{Scheme-Specific Funding}

\subsection{Origins}

The Pensions Act 2004 replaced an earlier regime where employers were required to meet a minimum funding requirement (MFR). This was "a rigid and weak approach and resulted in some employers contributing the minimum possible, rather than making contributions appropriate to the specific circumstances of their scheme. In the most severe cases, this underfunding left members facing significant losses in the event of a scheme wind-up" (The Pension Protection Fund (PPF) and TPR, 2016, para. 24). Myners' (2001) view was that the MFR regime was "distorting investment patterns without providing effective protection for members of defined benefit pension schemes" (para. 8.62). He recommended a "scheme-specific long-term approach based on transparency and disclosure, under which pension funds would report publicly on the current financial state of the fund and on future funding plans".

A "scheme-specific funding" approach was introduced with the Pensions Act 2004; the PPF \& TPR (2016, para. 26) explained:

"Valuations are based on assumptions agreed by trustees and employers, and any recovery plan will need to reflect the needs of the scheme and the strength and plans of the employer. In practice, this provides significant flexibility, enabling trustees and sponsoring employers to agree assumptions, funding targets and recovery plans that are right for the scheme and sponsor. It enables them to smooth out changes in valuations over the period of the recovery plan and results in the level of deficit recovery contributions paid remaining far more stable over time than the volatility in valuations would suggest".

The Act was also intended to comply with the EU Institutions for Occupational Retirement Provision (IORP) directive of June 2003, where section 15 referred to technical provisions in similar terms as the Act.

\footnotetext{
${ }^{2}$ The Occupational and Personal Pension Schemes (Disclosure of Information) Regulations 2013, SI 2013/2734.

${ }^{3}$ The Diageo Pension Scheme, Scheme Review 2017 is an example.
} 


\subsection{Discretion}

There are potential benefits in recognising the specific circumstances of firms to influence the management of a scheme. Of particular importance is the strength of the employer covenant, that is, its ability and willingness to support the scheme. For example, a mismatched investment policy that leaves a scheme exposed to large changes in the difference between the values of assets and liabilities may be more acceptable if the firm has a strong covenant. Potentially relevant factors include the firm's ability to pay dividends, the size of the scheme relative to the size of the firm and the options available to the firm to make changes in the scheme to cope with adverse situations (such as reducing benefits). Whether the firm has a need, in the short term, for cash to enable it to survive or develop would also be taken into account. On the other hand, if the firm has cash that is surplus to the requirements of the business, it may wish to pay higher contributions than otherwise. And while the employer covenant may be assessed with regard to the firm or firms that employ the scheme members, there is also a case for considering other firms in the group that may offer support in practice although not a legal obligation.

The different circumstances of firms are indeed important. The DWP (2017, para. 109) found considerable variation in deficit repair contributions as a percentage of pre-tax profit. So, as firms vary in their current financial position and future plans, there is merit in an approach that enables the actions taken to manage a scheme to reflect scheme- (including firm-) specific circumstances.

However, it is quite another matter for the assumptions of the actuarial valuation to be schemespecific. TPR's (2014) Code of Practice is explicit that there is discretion available in choosing a discount rate: trustees may use the flexibility available in setting the rate to reach a funding outcome that reflects a reasonable balance between the need to pay promised benefits and minimising any adverse impact on an employer's sustainable growth.

The problem is that discretion can obscure the true finances of the scheme. It enables the reported financial position of the scheme to be manipulated, for example, by using less prudence in the assumptions, so that the liabilities are given a lower value and the resulting funding ratio is higher than otherwise. A deteriorating financial position may be hidden. The author believes that in order to manage a scheme effectively, it is helpful to have its financial position reported on a consistent, rather than a potentially distorted basis, to help enable scheme-specific actions to be identified and implemented. Where there is discretion on the valuation assumptions, it is "very easy to create the impression that... funding is progressing smoothly from one valuation to the next, even though the underlying solvency position may have changed enormously, which will obscure the risk from members" (Cowling et al., 2005, page 82).

Further, the author believes that the information provided to members in the scheme funding statement is unhelpful. Consider members who are told that the funding ratio is $90 \%$. However, if the discount rate was calculated with a greater degree of prudence, it could be, say $85 \%$. Or if gilt yields were used, it could be, say $75 \%$. It is difficult to see what reliance members can place on the ratio they are provided with. The scheme funding statement does not contain the basis for calculating technical provisions which, anyway, members would find difficult to understand. The discretion results in the funding information provided to members having little meaning when the calculation basis is adjusted to meet the needs of firms and trustees. With a defined valuation basis that removes discretion, member communication would be less open to manipulation and easier to understand.

In practice, is there variety in the discount rate? The answer is yes. The DWP (2017, para. 17.2) found "considerable variation in the discount rates used at scheme level". The indicator used to assess this was the excess of the discount rate used (taken in "real" terms and converted to a single equivalent discount rate (SEDR) where more than one rate was used) over the 20-year real spot gilt yield. Since the discount rate reflects a (prudent) estimate of the expected investment return, this indicator is effectively a measure of the assumed outperformance of the scheme assets. The DWP (2017, para. 17.2) also found considerable changes in assumed outperformance over time. Indeed, 
Table 1. Distribution of the outperformance of the nominal SEDR over 20-year spot rate on gilts. (Source: TPR (2019), Table 4.9a)

\begin{tabular}{lc}
\hline $95^{\text {td }}$ percentile & $2.19 \%$ \\
\hline Upper quartile & $1.33 \%$ \\
\hline Median & $0.87 \%$ \\
\hline Lower quartile & $0.42 \%$ \\
\hline $5^{\text {th }}$ percentile & $-0.14 \%$ \\
\hline
\end{tabular}

$13.9 \%$ of schemes had a greater than $0.75 \%$ increase in assumed outperformance from one valuation to the next. Hence, it is not surprising that the government was "not convinced that there is strong evidence for a systemic issue with a lack of flexibility with the setting of the discount rate" (DWP, 2017, para. 17.1).

Evidence of variability in the discount rate (using the SEDR) is also available from data issued by TPR (2019) for valuations in 2016/17, see Table 1 . Further, the variability is not random. This is suggested by TPR (2019) data: firms with a deficit and a relatively long recovery plan (10 years or more) used a discount rate of $2.892 \%$ on average, producing rather lower technical provisions than where the recovery period was under 5 years: $2.653 \%$ on average.

Evidence from valuations for the purpose of pension scheme accounts suggests that pension scheme assumptions can be chosen in a biased manner. When examining the assumptions to measure DB pension liabilities in UK FTSE350 firms' accounts, Billings et al. (2017) found that weak schemes tended to use less prudent assumptions about price and salary inflation and the discount rate than strong schemes. Accounting rules restrict the discount rate to the yield on high-grade corporate bonds so that, while firms have some discretion on how to interpret this, that discretion is limited. It would be of interest to carry out similar research on funding valuations (although they are not publicly available in the same way as firms' accounts). However, given that discretion in assumptions is greater in funding valuations than for valuations for the purpose of firms' accounts, in particular as regards choice of discount rate, the author believes that it is reasonable to think that some bias will arise in choice of assumptions.

The Pension Schemes Bill (2020), as introduced in the House of Lords, proposes an offence of conduct risking accrued scheme benefits. Assessing whether an offence has taken place may be easier if there are valuations that do not involve the discretion on financial assumptions as currently available and which may lead to biased conclusions.

The concerns expressed above regarding discretion in valuation should not detract from the importance of scheme-specific management: rather, the contention is that clear and consistent valuation measures will provide better information to guide scheme-specific management.

\section{Benchmark Criteria}

Given the issues with scheme-specific valuations, it is appropriate to seek a benchmark valuation, on a basis defined by regulation, which can inform firms, trustees and members about the adequacy of the assets of the scheme in relation to the liabilities. The benchmark valuation can also be used for setting a funding target.

An alternative would be to have guidance on how scheme-specific assumptions are determined. The author believes that, while this may help, it is preferable to have a basis defined by regulation, to improve clarity and consistency, and avoid the discretion permitted by guidance.

Several types of actuarial valuations have been discussed in the literature. This paper is primarily concerned with solvency, and determining an appropriate measure of the solvency of a scheme 
that will be useful for the scheme sponsor, trustees, members and regulators, enabling them to assess the extent to which the assets are adequate for the liabilities and to contribute to decisiontaking. This is distinct from management decisions concerned with shareholder value and assessing the level of contributions to be made to the scheme, which may need additional information. While noting that solvency is sometimes considered by comparing the market value of assets with the buyout cost, this is only one of a set of possible measures; the author sets out a number of criteria that he regards as suitable for a benchmark valuation and then proceeds to identify the type of valuation he regards as most relevant to those criteria.

The criteria that the author regards as appropriate for the benchmark valuation to meet are

- based on sound principles, with reference to the actuarial and accounting literature;

- objective: involving fewer rather than more subjective assumptions (Dyson \& Exley, 1995);

- fair: Cowling et al. (2012, page 175) say "if two parties with conflicting interests are involved then neither party could claim that they were being treated unfairly treated relative to the other because of the actuary's own investment views of choice of assumptions";

- neutral: not biased;

- transparent and able to be communicated effectively to the parties involved; and

- feasible to be calculated for DB schemes of all types and including both small and large schemes.

\section{Benefits to be Valued}

Although the regulations require the technical provisions to be calculated using an accrued benefits method, there is more than one such method. The approach to valuing liabilities mandated under IAS 19 is the projected unit method (PUM), using the present value of benefits as accrued to the valuation date, but based on salary at retirement. IAS 19 (para. 67) also explains that where service in later years leads to a materially greater entitlement than service in earlier years, a straight line basis should be used to attribute benefit accrual evenly. The PUM was originally intended to be used as part of an exercise to determine rates of contribution to the scheme, with the intention that the rate be relatively stable. However, McLeish \& Stewart (1987) say that stability in contributions is not the primary purpose of pension funding; for the purpose of this paper, also the objective is not that stability but a proper measure of financial strength.

The position of a scheme when discontinued and the need to value the benefits should that happen were discussed by Gilley (1972). This was taken further by McLeish \& Stewart (1987) who proposed the "defined accrued benefits method" (DABM). The aim was straightforward: to define what was needed to secure the accrued benefits if the scheme is discontinued. The authors indicated that there was a range of possible values resulting, for example, depending on whether future salary increases were or were not included. Although they asserted that most employers using this method favoured an approach that led to more than the minimum value, it is arguably fair to say that, in present circumstances of scheme closures, a minimum value, without future salary increases, would be a fair representation of the DABM. This approach would also use accrual to date without the straight line method to reflect any higher later accrual rates.

Chapman et al. (2001) felt that the exclusion of future salary increases in the DABM was appropriate as part of determining a coherent method of funding DB schemes in the then current regulatory environment. And Cowling et al. (2005, page 70) argued

"If member security is the primary reason for funding a pension scheme, it seems consistent that the liabilities covered by this measurement should be the benefits payable in the event that the scheme is discontinued (setting aside deficits or benefit augmentation provisions) or the member leaves the scheme". 
Other actuaries have made the case for excluding future salary increases. The "current unit method" is a valuation as the PUM but omitting future salary increases. Exley et al. (1997) suggest that while future accrual is omitted as such accrual is, ultimately, at the discretion of the employer, it is arguable that future salary rises, while budgeted, are just as discretionary. Exley (2002) wrote "It makes no sense to regard future salary-related liabilities as an economic liability, any more than it makes sense to regard the future salaries of employees over their remaining working life as a capitalised liability today".

IAS 19 does require future salary increases to be taken into account, the basis for this being that the resulting benefit increases reflect an existing obligation and provide relevant estimates of future cash flows. However, accountants' views differ. Napier's (2009) paper on the logic of pension accounting came to the view that "Looking at the pension liability as a present obligation, it appears anomalous to argue that an employer does not have a present obligation to make future salary increases, but does have a present obligation to pay pensions reflecting future salary increases" (page 240). EFRAG (2008) point out two positions on whether the liability value should reflect salary increases. Some say that it should not. Others argue that the liability should reflect what the firm is committed to provide, which is benefits based on current salaries plus future salary increases, as this is a constructive obligation. Further, while it is arguable that a firm can withhold salary increases from an individual employee, that is not a reasonable stance if we think of the firm's obligations to its workforce as a whole.

Is it the case that salary-related benefits are a constructive obligation? Recent UK experience is that many firms have closed their schemes to new entrants or to future accrual or have imposed a limit on the level of salary or salary increase used to determine pension benefits. Although some firms continue to grant pensions that increase with salary, possibly subject so some limit, we cannot be confident that they will continue to do so. The author concludes that the case for regarding benefits that increase in line with salary as a constructive obligation is now much weaker, and the case for excluding future salary increases much stronger.

For a benchmark valuation testing solvency, the author concludes that future salary increases should not be used:

- excluding salary increases is helpful in determining the position on discontinuance;

- the benefits from salary increases are not an economic liability in the same sense as other pension liabilities; and

- the benefits from salary increases are arguably not a present or constructive obligation.

However, for a valuation to assess the recommended contribution rate, there is a strong case for including expected future salary increases (capped as applicable). This would lead to firms who are committed to pensionable salary reflecting future salary increases targeting funding to a higher degree than other firms (see Cowling et al., 2005). A similar argument could apply to firms where the level of benefit accrual increases over the duration of a member's service. However, for a benchmark for a solvency valuation, the author believes that a suitable balance between employer and members is represented by the defined accrual benefits method with no future salary increases.

\section{Valuation of Assets}

While the market value of assets is now the norm in valuations, this has not always been the case. In the late 1990s, the "discounted income valuation", while on the way out, was still not uncommon (Head et al., 2001). Indeed, market value is still not universal: while local authorities are rather different from companies, several authorities used, in their 2016 pension scheme valuations, a smoothed value over the 6 months around the valuation date. 
In the discounted income valuation, the asset value was the discounted value of an assumed income stream, with assumptions about increases in equity dividends and fixed-interest defaults, together with some "arbitrary factor" (Day \& McKelvey, 1964). The arbitrary factor was a number used to scale down the answer (to allow for the risks when the general level of dividends appeared unlikely to be maintained) or scale up (if artificial restrictions on dividends mean the dividend cover is abnormally high). This methodology was found to have several disadvantages (see Dyson \& Exley, 1995; Exley et al., 1997). In particular, Dyson \& Exley (1995, page 527) noted "the lack of confidence in any estimate of the long-term rate of dividend growth"; account needs to be taken of share buybacks and other forms of compensation for shareholders; and the asset value could be manipulated by making changes in the structure of the portfolio. Further, as derivatives made an appearance, they could not be valued suitably with this approach.

The discounted income valuation smoothed asset values when markets were volatile (Head et al., 2001). However, achieving this by constant parameters (income growth and discount rates) is questionable when economic conditions change, as Exley et al. (1997) pointed out in relation to the assumptions hard-coded into the MFR requirements. Non-market approaches to asset valuation were further questioned following the removal of advance corporation tax (Head et al., 2001).

Concerns were expressed if the discounted income valuation differed significantly from the market value of assets. If a shareholder has shares that the market values at $£ 80 \mathrm{~m}$, is it believable for an actuary to say that identical assets in a pension fund have a long-term value of $£ 100 \mathrm{~m}$ (Exley et al., 1997)? Can actuaries justify placing a different value on the assets compared to the market? If market values were lower, the result could be a significant shortfall in expectations regarding the pensions available if the scheme were discontinued.

It is still open to a firm and trustees to take decisions on the basis of a belief that a better representation of the value of assets would be obtained using a level of equity prices or interest rates, either current or expected in the future, which differed from the market view. Indeed, a survey of UK finance directors in 2010, shortly after the global financial crisis, showed that a majority tended to agree or strongly agreed that smoothing should be allowed in pension scheme valuations (Clacher \& Moizer, 2011). The author can understand that some would wish, in certain, perhaps unexpected circumstances, to see decisions such as contribution levels driven by non-market bases, possibly using a discounted income valuation or smoothed asset values. However, he believes that measuring solvency consistently with market values of assets is appropriate.

The development of accounting standards in recent years has tended to focus on the market value of financial assets. Using assets at market value and deriving market-consistent values of liabilities has also been more prominent in actuarial work since the 1990s, albeit not without controversy. In a pensions context, Arthur \& Randall (1990) showed "a great respect for market values" (page 13) and highlighted matching. A series of other authors (e.g. Dyson \& Exley, 1995) followed by promoting use of market values. IAS 19 requires a scheme surplus or deficit to be calculated using the market value of assets. Solvency II, the regulatory regime for insurers, uses a market basis for asset valuation.

It is also useful to mention, briefly, developments in insurance accounting and regulation. Some may question their relevance, as pensions differ from insurance. The nature of the difference in this context is not always clear. The author suggests some possible reasons, and why he regards it a still suitable to consider insurance:

- Insurance contracts have features that are not present in pensions, and insurance regulation may have different objectives and statutory frameworks that differ from pensions: the author does not suggest that pension valuations should replicate what is used in insurance, merely that we can learn from, though not necessarily accept, some of the principles involved;

- pensions are an arrangement involving a firm and its members, who have many interests in common, and the aim of paying pensions in full depends on the firm remaining solvent: the valuation informs the parties by identifying the dependence on the firm if there is a deficit 
but does not dictate what action is required, which it is reasonable to think should reflect considerations such as the firm's solvency and the interests of members, both employees and others;

- pensions have elements of discretion and may be reduced: accrued benefits are protected by regulation; areas of discretion in payments are now limited (while it should be noted that some areas of insurance, such as with-profits, also involve discretion); and

- pensions may be funded using equities whereas insurance is often not: some pension schemes are largely invested in bonds and some insurance funds have significant investment risks; in any event, the author will argue that the mix of assets is (largely) not relevant to the valuation of liabilities.

Market values have been the norm in insurance solvency valuations since the 1970s and are used in Solvency II, the regulatory regime for insurers. As regards assets in insurers' accounts, market value has become an accepted practice, although accounting standard IFRS 9 does permit bonds to be valued at amortised value. In an insurance context, Foroughi (2012) expressed concern that this may make it hard to compare insurers' results and introduce anomalies.

The author believes that market value rather than amortised value is appropriate for a benchmark solvency valuation:

- we need to allow for default risk, and there is merit in this being done automatically using market values rather than having to make estimates of the risk;

- while a "buy and hold" policy may be an element in support of amortised value, the long term of some bonds raises questions about whether current intentions to hold to maturity will turn out to be suitable if circumstances change;

- amortised values for some assets can lead to complications in ensuring that the value of liabilities is calculated consistent with this; and

- using market values for all assets simplifies understanding and helps bring clarity and consistency between schemes and over time.

Further support for market values is from Hatchett et al. (2013), who asserted that a scheme's assets will ultimately be valued at market value on the date of settlement (either by paying a benefit to a member or a transfer to another party such as an insurer), meaning that market values are relevant even if scheme decision-makers believe the market is distorted in some way.

However, it is recognised that there are issues when using the market value of assets.

There are some assets that are not commonly traded. For property, it is accepted practice for a professional surveyor to place a value on the asset. And, where a market value is unavailable, some derivatives are valued using a model; it is acknowledged that this can cause difficulties, but with no obvious alternative valuation method available.

The other problem is that market values are volatile and may be thought to be unreliable; financial crises may suggest that using market values is inappropriate, and falls in market values should not lead to knee-jerk reactions. One possibility is to use a "smoothed" value of assets which, while expected to be less volatile than a valuation using prices at one point in time, has issues:

- involves subjectivity in deciding how to smooth or otherwise adjust market values;

- means it is possible to smooth in a way that incorporates "abnormal" financial conditions even though conditions at the valuation date may be judged to be "normal";

- may be less easy to understand than one based on conditions extant at the valuation date (although it is accepted that liability valuations are also not easy to understand); and

- is not a suitable benchmark for common use when most schemes have adopted market values of assets. 
To address the issue of market values being variable and (to some) possibly irrational a solution is for the valuation to have sensitivities to show how the valuation (assets and liabilities) result would change if market conditions differed from those at the valuation date.

\section{Valuation of Liabilities}

\subsection{Fulfilment or Transfer?}

Should the liability be based on the liabilities being settled over time by the trustees (fulfilment basis) or by transfer to an insurer or other entity? The potential emergence of superfunds as a way to buy out $\mathrm{DB}$ scheme liabilities rather than through an insurer is a new development (DWP, 2018a). It remains to be seen how the pricing of superfund buyouts differs from an insurance solution; this paper focuses on the current practice of buyouts through an insurer.

The value of liabilities on the fulfilment basis is expected to be lower than using a transfer value, noting that an insurer:

- may make different assumptions regarding the level of interest, inflation and mortality (and other demographic assumptions that may be relevant);

- requires compensation to reward the risks (including investment risks) being taken;

- requires compensation for having to meet regulatory requirements, including maintaining a minimum level of capital;

- imposes a profit margin that may be more (or may be less) than warranted as compensation for risk, depending of the competitiveness of the buyout market; that margin to allow for tax as may apply;

- has costs of running the scheme, which may be higher (or lower) than those of the employer; and

- has transaction costs for implementing the transfer.

Funding is important because pensioners cannot rely on employers paying their pensions from revenue. The risk for scheme members is that the employer fails. If that happens, the benefits can be secured by a buyout. It is therefore important to carry out a valuation where the liabilities are assessed on a discontinuance basis, equal to the cost of transferring the obligations to an insurer. That is current practice in accordance with the regulations in force.

However, it is common for trustees, when disclosing the buyout cost in the summary funding statement, to say it is artificially high and not relevant when they are not planning a buyout. This reminds us of the development of IFRS 17, IASB's standard for insurance contracts, when original proposals for the liabilities to be valued as the "exit" market value ("transfer basis") were dropped in favour of a fulfilment basis on the grounds that insurance liabilities are typically fulfilled by the insurer and not transferred. Transfer is expected to inflate the liability value and would not be a neutral benchmark.

Solvency II for insurance is based around transferring liabilities to another firm, but that is specifically a requirement to reflect regulators' wishes to provide for such a transfer if the insurer fails, whereas we are here seeking a value that is "neutral".

The traditional calculation of a DB scheme funding ratio is based on the firm fulfilling its obligations to provide pensions and the cost of so doing.

Many DB schemes have transferred liabilities to an insurer. But, if a transfer has not been agreed, then if we wish to assess whether the assets are adequate for the liabilities, it is appropriate to work on the assumption that the firm will fulfil its obligations: a fulfilment basis is suitable for a benchmark valuation. We can then determine if the assets are on track to meet the liabilities.

\subsection{Discount Rate: Matching or Budgeting Approach?}

Discount rates are critical in pension valuations and it is a subject addressed by Cowling et al. (2012). The background to this paper is of interest. The management board of the Institute 
and Faculty of Actuaries (IFoA) recognised that there were issues about discount rates in actuarial work and commissioned a report on the subject by Patel \& Daykin (2010). The board then appointed a group of senior actuaries with different backgrounds (insurance, pensions and investments) to review the report and prepare a paper which was presented at meetings of the actuarial profession and subsequently published in the British Actuarial Journal; it won the prize for the best paper by IFoA members in 2010/11.

The paper considers a valuation to assess the financial strength of a scheme assuming there is no other supporting financial entity; the valuation result can then inform what support is required. In this context, the authors concluded that a valuation to assess the assets required to meet liability cash flows should use a "matching" approach. Here, "the discount rates are consistent with the current market value of assets that, as far as possible, replicate the (future) economic behaviour of the liabilities to which the discount rate(s) might be applied" (page 170). This is consistent with the "law of one price", where a set of cash flows has one price as, otherwise, an arbitrage opportunity arises. The authors also said, "Where objectivity and fairness between parties is paramount, and the assets and liabilities in question are essentially already contracted arrangements then a matching, i.e. market-consistent, approach, is nearly always likely to be preferable" (pages 175-176).

An alternative, "budgeting" approach, is where the discount rates are consistent with the expected returns on the assets expected to be held. According to Cowling et al. (2012), this is suitable where the objective is advising on the accumulation of assets to meet the liability cash flows as they fall due (although it does not solve the problem of insufficient assets if the sponsor does not rectify a shortfall before adequate assets have been built up). Exley et al. (1997) state that, strictly, such techniques "do not result in a liability valuation at all but rather a statement that a certain set of assets '100\% fund' a set of liabilities” (page 850).

Cowling et al. (2012) applied their conclusions to measuring the solvency of DB pension schemes. They were critical of present practice where the emphasis is on the technical provisions, using a budgeting approach and a discount rate of the (prudent) expected rate of return: "from a member's perspective this information is of limited use" (Cowling et al., 2012, page 179). Again, "member communication based on a budgeting calculation gives misleading information about the security of members' benefits" (Cowling et al., 2017, page 60). Instead, Cowling et al. (2012) concluded that pension scheme solvency should be estimated using a matching framework and, in disclosing the funding position to members, trustees and regulators, the focus should be on "the solvency position and how it is expected to develop under the agreed funding plan" (page 179). The author's view is the same: it is not a communication issue as such - improving the communication of a result based on a budgeting basis is not the solution, which should be to communicate using a matching basis.

Cowling et al. (2012) did refer to the possibility that some blending of matching and budgeting approaches may be appropriate, involving matching calculation constraints on the budgeting approach. This could be relevant to, for example, a DB pension scheme where some liabilities are more contractual and some less. The Institute and Faculty of Actuaries (2012) referred to the possibility of a blended approach in some situations. However, significant discretionary elements in DB schemes benefits are now uncommon, and the author feels that there is no reason for the solvency of a scheme to use some blended approach, the justification for which and operation in practice are not clear. Indeed, when Cowling et al. (2012) applied their thinking to DB scheme solvency, it was clear that they regarded a matching approach as the one to take.

For a DB pension scheme, what are the matching assets? Cowling et al. (2012) say that under a matching methodology the present value of a 10 -year cash flow is calculated with reference to the market price of a 10-year bond. While this implies bonds as the match for pensions that are deferred or in course of payment (index-linked bonds as appropriate), aren't equities a match for salary-related pensions? The analysis and modelling of Exley et al. (1997) concluded that cash or bonds match fixed pension liabilities; inflation-linked bonds for inflation-linked labilities; for 
salary-related liabilities, equities were a poor match: "we would find it very difficult to justify any match between equities and salaries if index-linked bonds were available as an alternative" (page 898). Other authors have concluded similarly, for example, Chapman et al. (2001) concluded that the value of any cash flow stream is equivalent to the value of a matching asset: for DB pensions, bonds were the matching assets.

A further possibility is to use swaps, with a credit risk adjustment for bank default, as prescribed by Solvency II. Hatchett et al. (2013) suggested that, in the UK context, readers might think of risk-free assets as gilts or suitably well-collateralised swaps with a sufficiently reliable counterparty. Charmaille et al. (2013) regarded the normal position to be for swap rates to exceed gilt yields, although this could be reversed in certain circumstances; Foroughi (2012) put forward possible explanations for negative swap spreads at medium to long durations. The PPF's liabilities are referenced to the higher of gilt yields and swap rates. This is similar to Foroughi's (2012) "minimum cost" valuation premise: where government bonds and swap asset classes are deep and liquid and form a good match for (insurance) liabilities, the more favourable result should be used. He put forward several reasons for preferring this "minimum cost" approach, including markets not always being perfectly efficient, and the benefit of reducing the risk that one calibration instrument is subject to high demand simply because of the market-consistent valuation. The author regards this as a suitable way ahead for DB schemes, although it is fair to admit that this may complicate communication of the valuation result.

The consensus of recent actuarial research has highlighted the case for solvency valuations using discounting at the yield on matching assets, with no recent papers suggesting that equities would be a good match for salary-related benefits:

- Exley et al. (1997) argued that scheme solvency should be assessed with discounting based on the matched, not actual assets (i.e. cash and bonds);

- Head et al. (2000) found that an economic valuation using gilts is entirely objective and most satisfies (compared with other valuation types) targeting security as it targets the defined benefit in the event of scheme wind-up as well as at projected retirement age;

- Chapman et al. (2001) proposed discounting liabilities at bond rates to produce a marketconsistent valuation;

- Cowling et al. (2005) recommended solvency be assessed by reference to a notional investment strategy with assets providing defined benefits with a high degree of certainty such as gilts, AAA debt or collateralised swaps;

- Cowling et al. (2012)'s paper indicated that solvency measurement should use the discount rate on matching assets, which for DB liabilities were gilts;

- Hatchett et al. (2013) concluded that a valuation based on financial economics has several benefits, including providing a more objective measure of the pension promise; this would mean discounting at the yield on matching assets, that is, low credit risk assets such as indexlinked gilts, insurance contracts and swaps; and

- Cowling et al. (2017) stressed that a solvency valuation should use a matching framework, the matching assets being bonds or possibly other assets that generate a known series of cash flows.

Using discount "rates" rather than "rate" is important: account has to be taken of the term structure of interest rates (Exley et al., 1997).

It is useful to look at accounting standard-setters' approaches, not to apply them to pension scheme valuations mechanically, as they have different objectives, but the conclusions and their rationale may suggest approaches that are helpful. The (UK) Accounting Standards Board (ASB), when developing a standard for pensions accounting in the late 1990s, proposed in its Discussion Paper that the matching assets were gilts for pensions that were deferred or in payment but equities for salary-related pensions. However, following the research of Exley et al. (1997), it accepted 
that bonds, not equities, were the answer. When FRS 17 was issued in 2000, the discount rate was set as the rate on high-grade corporate bonds rather than gilts: this was because employers have an option to offer benefits lower than the best estimate of cash flows in the valuation of liabilities. For example, equity investing may lead to a surplus that is used to increase members' pensions. Hence, the ASB felt that discounting using gilts would overstate liabilities. In an ad hoc approach, they decided to use the yield on high-grade corporate bonds. For the international standard, IAS 19, the IASB decided that the discount rate should reflect the time value of money and decided on highquality corporate bonds (but, if no deep market in such bonds, government bonds). EFRAG (2008) suggested using a risk-free rate and the ASB confirmed its view that a risk-free rate should be used (EFRAG, 2009). It is the case in the UK that gilts would better reflect the time value of money or a risk-free rate than would corporate bonds. Indeed, to review the rationale of FRS 17, there is now little expectation that members will receive benefits above the minimum in scheme rules. The case for using risk-free yields is therefore strengthened. To illustrate that this type of approach is acceptable in accounting, it is used in IFRS 17 for insurance contracts.

It is therefore concluded that the adequacy of assets to meet DB pension liabilities should be measured with the liabilities discounted using risk-free yields. We would expect the UK pensions regulator to start considering gilts, including index-linked gilts, as an appropriate way forward. With respect to the argument that gilts are not risk-free, constructing a hypothetical rate curve deemed to be totally free of credit risk has its own difficulties, and Foroughi (2012) accepts "suitably low credit risk" as the way ahead. There are potential complications arising from some pensions having a minimum price indexation (0\%) and a maximum; these can be addressed by deriving a hedge of gilts and index-linked gilts (Exley et al., 1997).

There are two areas where the gilt/swap approach needs adaptation, being areas of basis risk referred to by Charmaille et al. (2013). One arises from the absence of assets with maturity terms over 50 years, also considered by Cowling et al. (2012), who discussed possible ways of dealing with this. Second is the lack of CPI-indexed assets, an issue which the PPF monitors in its management reporting (Charmaille et al., 2013).

In contrast to market-based valuations, the common valuation practice, consistent with the regulations, uses a budgeting framework to calculate technical provisions, which takes advance credit for the equity risk premium. This does not, however, provide information on the solvency position of the scheme, which Cowling et al. (2012) and (2017) regard as requiring a valuation using a matching framework. Matching involves considering a notional portfolio, so that the assets do not affect the liabilities, subject to secondary considerations such as stranded surplus and credit risk (Exley et al., 1997; Cowling et al., 2017).

To make the point with an example taken from Exley et al. (1997), consider a firm that offers a guaranteed sum of $£ 110$ in a year's time and invests $£ 100$ now in equities with an estimated return of $10 \%$, when gilts yield $8 \%$. Equities (where the return is not guaranteed) are not a match for a guaranteed liability. So, while the fund may end up with more or less than $£ 110$ and, on average, appears to break even, the fund has not received any compensation for the risk it is taking. Therefore, the value of $£ 110$ guaranteed a year ahead is not $£ 100$ now, even if equities expect to return $10 \%$. Indeed, if shares in one firm $\mathrm{X}$ are expected to perform really well, with an expected return of $20 \%$, could the firm use this to guarantee $£ 120$ ? (no).

Cowling et al. (2005) are concerned that using a discount rate higher than that derived from a matching portfolio is simply a way of reducing the contribution rate at the expense of higher contributions later and lower member security: "an element of self-delusion within the actuarial profession" they called it (page 78). Hatchett et al. (2013) accept that, while schemes may wish to take investment risks in order to reduce the cost to the firm, they have a concern that, under current regulations, stakeholders "could change the asset allocation to 'hide' the deficit" (page 292). The author would say that using a budgeting framework means that the liabilities appear to magically reduce if the firm decides to adopt a more risky investment strategy with higher expected returns, and that this is quite wrong: the liabilities depend on factors such as service, 
salaries and mortality. Indeed, as Hue et al. (2019) stated, "The 'liabilities' are really the estimated cashflows rather than the capital amount. Thus, the liabilities do not depend on the discount rate" (page 25). The author believes that, in contrast, a market-based view achieves greater objectivity, clarity and consistency.

It is fair to add that one paper, a report for the National Association of Pension Funds by Clacher \& Moizer (2011), recommends the liabilities be discounted at a rate that reflects the scheme's investment strategy, and this to be combined with a value of assets smoothed to reflect the long-term nature of the pension obligation. However, Clacher has clarified that this proposal is specifically in relation to company accounts rather than valuations for trustees, etc (see comments in the discussion on Hatchett et al., 2013).

Recent years have seen interest in so-called "self-sufficiency", with a survey by Mercer finding $47 \%$ of schemes are looking at this as their long-term objective (Dodds, 2018). Cowling et al. (2017) suggest a number of possible ways to interpret what is meant by a self-sufficient scheme, typically implying a low level of reliance on the employer, although they add their view that a layman would interpret it as a scheme no longer reliant in any circumstances from the employer, implying that the assets should be sufficient for a buyout from an insurer. Some low mismatched investment risk may be regarded as optimal by trustees and firm, and a discount rate may be selected to equal the expected return on such a basis. However, as this is not a matching portfolio, the expected returns do not produce a discount rate to use to measure solvency in accordance with the matching principle.

Integrated risk management has been promoted by TPR (2018), which has said that the discount rate chosen should reflect risk management principles and be consistent with, inter alia, the view of the employer covenant, with a weak covenant being associated with a relatively low discount rate. That would lead to the liabilities being given a high value and could lead to a recovery plan and higher contributions than otherwise, arguably appropriate for an employer who may be unable to meet its obligations. However, Cowling et al. (2017) found that the link between covenant and discount rate is, in practice, quite weak. Subsequent data from TPR (2019) suggest the link may no longer exist. In any event, we ought not expect the discount rate to be affected by the covenant: the liabilities depend on salaries, mortality, etc and are not affected by the employer's covenant (aside from credit risk and stranded surplus). The author's view is that scheme-specific management is best done with clear and consistent solvency valuations, and a weak covenant can in itself be persuasive of the need for a low-risk investment strategy and higher contributions without needing to adjust or benefitting from adjusting the valuation result.

\subsection{Liquidity Adjustment or Not?}

Another factor is in place: "Pension promises are typically illiquid, and hence the matching portfolio should also contain illiquid assets" (Chapman et al., 2001, page 618). Charmaille et al. (2013) mention this as a possible future development in managing the PPF.

Liquidity adjustments have been the subject of much debate, especially for insurers with a portfolio of annuities. Keating et al. (2016) described liquidity as "the degree of inter-exchangeability of money and the asset" (page 7). However, there are some tricky issues. We think of liquidity as an attribute of assets: how easily can they be traded and with what impact on price. How does liquidity relate to liabilities, when they are typically not traded? Foroughi (2012) refers to different ideas on a liquidity adjustment: either using

- a concept of a hypothetical asset that matches the characteristics of the liability outflows, including liquidity or illiquidity; or

- derived from the return on achievable viable asset-liability management strategies.

We can consider an annuity as an asset itself in the hands of the policyholder who, unable to trade the annuity requires compensation for this illiquidity (Browne et al., 2003). However, this 
does not translate into how we might adjust the valuation of an insurer's (or DB scheme's) annuity liability. There are a number of approaches to isolate what is often referred to as the illiquidity premium (in terms of the yield on assets), though one could also start from the basis that liquidity has a cost (Keating et al., 2016) and hence there is an illiquidity discount, that is, the value of illiquid assets (and liabilities) is below the value of the corresponding liquid cash flows.

In Solvency II insurers may, in specified circumstances, use a "matching adjustment". Here (and this is to simplify a complex process), insurers can discount future predictable cash flow obligations at the usual risk-free rate plus the excess of the yield on "matching assets" they have over the sum of the risk-free rate and a "fundamental spread". That spread reflects the compensation for risks to which the insurer is exposed, dependent on the likelihood of default; it is argued that, on corporate bonds, the excess reflects the compensation, or "liquidity premium" for the risk that insurers may have to sell into secondary bond markets when credit spreads are wide (Rule, 2018). Annuity providers with matching assets are not exposed to this risk and can therefore earn the liquidity premium if they can bear the credit risk and hold the assets until maturity (Rule, 2018).

The average matching adjustment for corporate bonds was around 120 basis points at 31 December 2016, although the benefit was even greater for illiquid assets such as infrastructure loans or equity release mortgages, where the matching adjustment could support an increase in the discount rate of about 150 or 200 basis points, respectively (Rule, 2018). These might be termed "illiquidity adjustments" (IAs), reflecting the additional yield from holding assets to maturity and avoiding the risk of early cashing in. They are consistent with Dullaway's (2009) argument that there are times when there are multiple ways of constructing replicating portfolios that are essentially risk-free and which match annuity portfolios, in which case it is reasonable for insurers to use the cheapest way to value annuity business. Similar is the argument that the discount rate in Foroughi's (2012) "minimum cost valuation" need not be restricted to government bonds and swaps as other assets may be able to match insurance liabilities. In principle, arbitraging opportunities should limit the possibilities, so this may turn out to be not material. The author's view is that the use by DB schemes of illiquid assets suggests that, if the allowance for credit risk in their yield is removed, they could, in principle, be incorporated in a minimum cost valuation.

The Solvency II matching adjustment is available only if the insurer holds the assets concerned, and one possibility for pensions regulators is to allow an IA that is supported by assets the scheme holds. However:

- this is contrary to the principle of a matching framework as suggested: it would mean that two schemes with identical obligations could show different liability values depending on the assets they had (breaching the principle discussed earlier that the valuation of liabilities is not materially affected by the asset mix);

- there may be an undue incentive to move into assets that can lead to an IA credit, especially if the assets are complex to understand and manage, and a pensions regulator may have concerns about pension schemes being led to take more risks with illiquid assets, especially as regulatory oversight on pension schemes is less intrusive compared with that for insurers under Solvency II; and

- it could be administratively complex and costly, especially if an approach similar to Solvency II is taken.

If an IA is available independent of the assets a scheme holds, a potential issue is that if a scheme holds gilts and swaps equal in value to the liabilities after discounting using an IA, we would not expect the liabilities to be met in full. Trustees need to be clear on whether their policy is to choose assets that earn an extra return as a reward for holding to maturity. This reinforces the need for schemes to document their approach to financial management. 
Should the discount rate then use the highest possible IA? This highlights the situation where we have different yields apparently "as if risk-free", having accounted for the fundamental spread. It is therefore reasonable to suppose that some (especially the higher) IAs will reduce over time (see Rule, 2018) and indeed pension funds have found that increased competition for a higher rate of return is leading to the reward for illiquidity declining (Government Actuary's Department, 2018).

Other factors suggest caution in using IAs. There are several ways to estimate the extent to which yields reflect risks not borne by the entity holding the assets to maturity, each method having issues (Telford et al., 2011; Foroughi, 2012). Care is needed in assessing the fundamental spread with illiquid assets that are not rated (Rule, 2018). Further, since DB schemes offer options, including transfers to other schemes and cash commutation at retirement, it would be less easy to apply an IA for pre-retirement liabilities. Indeed, Duval (2019) commented that "most managers these days will tell you the illiquidity premium is zero or possibly negative" (page 5). On this basis, it would be fair to accept a pensions actuary concluding that using an IA would be inappropriate or immaterial.

It could be argued that a scheme with projected positive cash flow for some years is not subject to significant risk of shortfalls arising from early encashment of assets, this justifying an IA of greater size than otherwise. It is fair to say that an open scheme is more able to invest in illiquid assets without having to sell them to pay pensions (Salt, 2019). That may well lead to a higher IA. However, there is a need to consider the possibility of the scheme ceasing to admit new entrants and/or closing.

IFRS 17 for insurance contracts requires the discount rate to reflect, inter alia, the liquidity characteristics of the liabilities. It is not yet clear how this will be interpreted and implemented. Since life insurers will need to consider their annuity portfolios, it could be useful for life and pensions actuaries to work together in researching the issues of illiquidity.

Pensions regulators may conclude that they should not allow any IA as theory and research as incomplete, but this could produce an upward bias in the calculation of liabilities.

One possibility is an approach whereby schemes discount at a risk-free rate (higher of gilts and credit risk-adjusted swaps) plus a factor that reflects some IA that would be available, independent of the assets actually held, but as if the scheme used assets such as corporate bonds and illiquid assets for part of its portfolio; this either only applied or only applied fully to the post-retirement liabilities. In principle, the IA varies by scheme characteristics and will change over time. TPR may wish to question how an actuary determines an IA that has been used, and it would be hoped that experience would build up over time.

\subsection{Allow for Credit Risk or Not?}

Since the objective of the valuation is to ascertain how members' entitlements compare with the assets of the scheme, should the liabilities be reduced to reflect the credit risk of the firm rather than be calculated at a risk-free rate? Current practice both in valuations for trustees and for the accounts is not to allow for the firm's credit risk; the basis for conclusions for IAS 19 explicitly rejected allowing for credit risk on the basis that a weak firm would then show a lower level of pension liabilities.

Ralfe et al. (2018) put forward an alternative whereby the discount rate is the market rate on bonds with a similar obligor to the employer, taking account of the security provided by the fund assets. This allows for credit risk. It may well be a useful calculation from the perspective of the employer in assessing the expected burden of its pension obligations. There can be some practical difficulties. In particular, if the firm has not borrowed on the market, the required discount rate is not readily observable; to discount pension obligations we need rates at different durations, including durations longer than the typical length of corporate borrowing; and the discount rate needs to take account of the assets already in the fund. 
The actuarial literature supports solvency valuations making no allowance for credit risk:

"It is fundamental that, whenever a liability is subject to credit risk, it is benchmarked against the payment required to meet the liability in full, were it not subject to credit risk ... If actuaries include an allowance for credit risk in assessing the liabilities, this obstructs members and trustees from assessing the credit risk themselves" (Cowling et al., 2005, page 71).

The profession's discount rate project came to the same conclusion: a solvency valuation should compare the assets with the value of commitments to members, which requires no allowance for credit risk (Cowling et al., 2012). Such allowance is a separate, albeit related, issue (Cowling et al., 2005). It may be good practice for actuarial valuations to also calculate a figure for liabilities with allowance for credit risk. Indeed, the solvency figure on its own is just one figure and does not tell us the whole story.

The author's conclusion is that allowing for credit risk is inappropriate for a benchmark valuation on solvency as it is more geared to the needs of the firm (although still relevant for members) and requires more assumptions than a valuation with no allowance.

\subsection{Best Estimate or Not?}

The valuation of liabilities requires assumptions about several matters which affect future cash flows: mortality in particular, and other demographic factors such as the proportion of members who are married; member options, including cash commutation; and expenses. Since we are using a matching approach and aiming for a valuation which is neutral between members and employer, the cash flows should be at the expected value. Given the uncertainty involved, it is appropriate to use probability-weighted outcomes. This is consistent with IFRS 17 and Solvency II for insurance contracts.

The author regards this as preferable to using the term "best estimate" (as in IAS 19), which is open to differing interpretations.

In some cases, the probability-weighted expectation may be approximated by a single future assumption, for example, one mortality table instead of a series of future mortality assumptions weighted with probabilities. This recognises the difficulty of attaching probabilities to a range of uncertain outcomes, often some long time in the future.

While regulations would prescribe the use of expected values, scheme-specific information on demographic and similar variables, notably mortality, would be considered in determining the precise assumptions to use.

\subsection{Prudent or Not?}

Should the assumptions be prudent assumptions? Since we are seeking an unbiased measure of liabilities, we wish to know how best they can be represented rather than err on the high side. Hence, if prudence means assumptions which are biased in favour of overstating the liabilities, then the answer is no. As Cowling et al. (2012) stated in the context of the discount rate, "matching valuations contain no concept of a prudent valuation: the market value of a matching asset portfolio is a single number, not a distribution" (page 208). Mortality, expense, option and similar assumptions could be prudent, and Cowling et al. (2005) indicated that this should not be controversial for a solvency measure; indeed, they asserted that negative options available to parties not running the scheme should be allowed for fully. Indeed, following the IORP Directive, assumptions in technical provisions in pensions have to be chosen prudently, taking into account the firm covenant. However, prudence in the sense of producing a liability value higher than the expectation produces a biased estimate, which the author argues is inappropriate for the benchmark. 
It is useful to add the thinking of the International Accounting Standards Board (2018) in saying that prudence is the exercise of caution when making judgements under conditions of uncertainty but does not mean that assets or liabilities should be either overstated or understated. This view of prudence is useful in interpreting the IORP Directive.

It is also noted that IRFS 17 and Solvency II for insurance do not add margins as part of the liabilities, specifically for prudence.

Prudence is also a problem as there is a divergence of answers as to what constitutes prudence and no right answer (Cowling et al., 2005). And prudence may also lead to difficulties regarding transparency. The reader of the resulting report may, even with extensive disclosure, find it difficult to understand what prudence has been incorporated and what its effect is. For example, if it is stated that, to be prudent, mortality rates have been assumed to decrease at $1 / 2 \%$ p.a. more than expected, what does the reader make of it? The author regards it as more appropriate to use expected values for assumptions and then have risk disclosures that illustrate the effect of variations on those assumptions. A consistent series of valuations using expectations is argued to be clearer than one where prudence is built in and may be varied from one valuation to the next, thereby hiding what has been happening. Prudence may produce unwarranted complacency or may provoke undesirable consequences if pension obligations are thought to be more onerous than they really are.

It is very welcome to have prudence in the management of pension liabilities: trustees must understand the obligations to and expectations of members and acknowledge the implications of the scheme for the employer who has a business to run. There is a need to balance different interests and avoid reckless risk-taking. But prudence in management does not mean there has to be prudence in accounting, if that were to mean inflating the level of liabilities beyond what is derived from using expectations.

\subsection{Risk Margin or Not?}

As an employer with a DB scheme has committed itself to a liability that is uncertain, it needs to ensure it can meet its obligations even in the event of adverse outcomes when assumptions turn out to differ from expectations. Hence, it can be argued that a risk margin should be added to the expected value of the liability.

To begin reviewing ideas on the subject, IFRS 17 requires the liability value on insurance contracts to include a risk margin, meant to be what the insurer would pay to have a certain rather than uncertain liability with the same expected value. If we assume that the insurer is seeking to maximise shareholder value, then the risk margin is the effect on shareholder value of the uncertainty. Such a risk margin is surprising, as firms' financial statements do not account for shareholder value. In any event, this would not be suitable for a benchmark valuation of a DB scheme: reflecting shareholder preferences would mean it is a biased rather than a neutral figure, aside from the severe difficulties in calculation.

Value at Risk (VaR) and Tail VaR have been put forward as possibilities for the risk margin under IFRS 17 (see International Actuarial Association, 2018), and while they do not provide a link with shareholder value in accordance with IFRS 17, this does not disqualify them as candidates for a risk margin for a DB scheme. Cowling et al. (2005) suggested a VaR measure for margins for risks that cannot be matched. If a VaR or similar approach is to be pursued, there are issues of what percentile in the probability distribution to use, together with the practical problems of establishing the probability distribution of not only mortality but other demographic variables, expenses and options as well. Noting that options such as cash commutation are subject to change if regulations change exemplifies the problems. Communication of the result may also be a challenge: a comment such as a $95 \%$ risk level needs to be understood to cover risks that are not investment risks (which, in practice, are likely to be the main risks).

Difficulties of quantification were the reason that EFRAG (2008), when considering pension liabilities in a firm's accounts, concluded that although liabilities should reflect a risk margin, a 
better approach is to disclose the sensitivities of the liabilities to changes in the assumptions. Similarly, Cowling et al. (2012) indicated that a series of stress tests was a way forward.

The PPF looks to have $90 \%$ confidence of meeting unexpected claims over 5 years and longevity risk over the remaining lifetime of the fund and estimates that a margin of $10 \%$ of liabilities is required for this (Charmaille et al., 2013). The $10 \%$ is not fixed but will be re-evaluated as conditions change. Other schemes could make calculations to derive figures suitable for their circumstances. One possibility is for pensions regulators to impose some similar type of risk margin for non-investment risk unless a scheme demonstrated that it was inappropriate in its case.

Now consider another possible approach to the risk margin: the amount needed, above the liabilities, to enable another firm to take over the liabilities. This is the rationale of the risk margin in Solvency II; we need not here be concerned with the controversies around the calculation method prescribed. In a DB context this is the amount that, when added to the liabilities, gives the buyout cost.

The importance of the buyout cost is illustrated by it already forming part of the existing communication to members. Cowling et al. (2012, page 178) say that "Regulators and others are increasingly driving the purpose of funding a pension liability to be to provide security for members' benefits in the event of the employer becoming insolvent". Indeed, if the pension assets are there to provide security if the employer is no longer there, then it is what happens in that event that is important. If the firm is insolvent and the result is a buyout, then it is the buyout cost that matters.

Using the buyout cost as the risk measure is relatively straightforward given that it is already calculated as part of the valuation process, although usually an approximation based on the actuary's knowledge of the market rather than a response to a specific quotation request. It avoids the problems of a calculation involving $\mathrm{VaR}$, etc or the effect of risk on shareholder value and appears to be a reasonable approach for determining the risk margin for a DB scheme.

Should the risk margin form part of the liabilities as reported? This would lead to the liabilities being reported at a higher a level than was expected to arise. This is inconsistent with the requirement set that the benchmark valuation be unbiased, and the author therefore concludes that the answer is "no". Further, if the risk margin were as suggested above, this would lead to the liability being the buyout cost, and we know from current practice that trustees could suggest that scheme members pay little regard to it.

However, trustees may rightly be concerned at the prospect of not having enough assets in their fund in the event of adverse experience. It is understandable that they may wish to retain some or the whole of the risk margin in the fund to ensure they have assets under their control if risks turn out badly, in the sense of leading to the solvency position being less favourable than projected. On the other hand, a firm may argue that it is an inefficient use of its resources to fund against unexpected risks, which may not arise and if they do arise, may be offset by other risks turning out better than expected. It would also increase the possibility of stranded surplus.

There is merit, from the perspective of trustees and members, of a risk margin being included in the fund. There are a number of possibilities as to what trustees should aim for (VaR, Tail VaR, stress tests, etc). The measures of risk available, covering both investment and other risks, can inform discussion between trustees and firm on what funding for a risk margin could be acceptable.

The author does not propose a regulatory measure for a risk margin to be held in the fund. This reflects

- there is no clear objective answer for a risk margin; what is optimal depends on the needs of trustees/members and the firm;

- rejection of proposals for an amended IORP Directive to include a specific amount of capital requirement; 
- regulators and trustees will have access to risk disclosures, which can inform discussions on funding; and

- the need for further research on liability measures currently used and as proposed here and the quantitative impact of possible risk margin measures.

Hence, the conclusion is that a risk margin should not be included in the reported liabilities; while employer and trustees may agree some risk margin to be held in the fund, this would not be required by regulations; and disclosure of the buyout cost should continue.

\subsection{Conclusion}

The benchmark liabilities would, as part of a solvency valuation, be prescribed as:

- the benefits on discontinuance;

- discounted using the greater of gilt yields and swap rates;

- with, in principle, an "illiquidity adjustment" reflecting the way an annuity is illiquid, allowing schemes to hold assets without exposure to the costs arising on early sale and earning a yield above that on gilts/swaps, this adjustment being independent of the assets held; and

- a probability-weighted expected set of assumptions for mortality, etc.

The valuation process would also estimate the buyout cost.

However, a valuation with just two numbers, assets and liabilities, is insufficient. Risk is important, even if a scheme is closely matched on investment strategy; $100 \%$ funded on a solvency basis now does not necessarily mean $100 \%$ funded in the future. Section 7.9 refers to risk disclosure, including sensitivities.

\subsection{Risk Disclosure}

The valuation needs to be accompanied by risk disclosure, taking account of risks from nonmatched assets as well as non-financial risks. One way is to use sensitivity tests, covering both assets and liabilities, the latter encompassing not only financial but also other risks, in particular demographic risks. A simple possibility is to start using the method (or something similar) of calculating "stressed" assets and liabilities in determining the levies that schemes pay (Pension Protection Fund, 2019), for example, UK equity prices falling by $19 \%$ and nominal interest rates reducing by 0.75 percentage points. The DWP (2018a) suggested TPR could issue a code of conduct to include stress tests and sensitivity analysis for superfunds, and such an approach could be used for DB schemes in general, and may go beyond what is currently included in some DB scheme actuarial valuation reports.

An alternative is a stochastic analysis, which can encompass variability in both assets and liabilities and give a full range of probabilistic outcomes. Cowling et al. (2017) expressed a preference for using asset models with economic scenario generators to determine confidence levels. Models can be valuable in indicating risks and in identifying the scenarios that produce the most adverse results, enabling decisions to be taken on whether risk mitigation is needed. The DWP (2018a) has suggested stochastic modelling as one possibility as part of a new regulatory framework for superfunds.

Important issues with stochastic analysis are model risk, highlighted with the global financial crisis of 2008; model manipulation (Mariathasan \& Merrouche, 2014); the cost of undertaking the work, which may not be warranted for small schemes; limited evidence on the probabilities of some assumptions and the challenges in communicating the outputs, assumptions and uncertainties.

Pensions regulators may nevertheless wish to use, in their monitoring work, risk measures from stochastic analyses that schemes produce and to require such analysis from schemes if not otherwise available. 


\section{Assessing the Contribution Rate}

We now have a calculation of assets and liabilities; say there is a deficit. If the trustees' policy is to have matching assets, then the deficit is what the firm needs to contribute, usually spread over time. However, it is common for schemes to take some investment risks by mismatching.

A way forward to calculate required contributions is to discount future cash flows at the expected yield on the assets in the fund: the budgeting framework. Cowling et al. (2012) recommended a budgeting framework with a realistic estimate of the expected investment return. Indeed, this may indicate that no deficit contributions are required if the expected return is sufficiently high. A difficulty, of course, is if the employer is weak and the scheme closes before the expected investment returns have been achieved, when the assets are then inadequate to pay the liabilities. The budgeting framework works better in the presence of a strong employer.

Using an "expected" basis for assumptions avoids the question of what degree of prudence to use, whether it is understood, and leads to either complacency or undue caution. The valuation output would then focus on the solvency position at the valuation date and how it is expected to develop under the agreed funding plan (see Cowling et al., 2012). In addition to sensitivities, stochastic analysis may have a large role in highlighting the risks to the solvency position, and the outcome - a prudent approach to management - may involve paying higher contributions or a lower recovery plan period than the valuation with the expected rate of return implies.

If the approach suggested for solvency valuations and setting contribution levels requires amendment to the Pensions Act 2004, then either the Pension Schemes Bill (2020) or other future legislation may be the way to arrange this.

The actuarial valuation which assesses the solvency position in accordance with the suggested framework may well be the suitable vehicle for including an assessment of the recommended contribution rate assuming some expected rate of return on the assets that exceeds risk-free yields. The author highlights the approach taken by Hatchett et al. (2013), where:

- the economic value of liabilities is calculated, discounting at gilt yields (L);

- the market value of assets (A) is lower;

- the extra return, above gilt yields, from investing some assets in equities, with an equity risk premium, and from an assumption that gilt yields will increase, is calculated (R);

- the firm contributes (L) - (R) - (A) to make up the deficit;

- this is equivalent to calculating technical provisions, using expected rates of return, as $(\mathrm{L})$ - (R), that is, a shortfall of $(\mathrm{L})-(\mathrm{R})$ - (A) to be made up by the firm's contribution.

The above is an interesting way for actuaries to report on solvency and contributions so that their relationship is understood. However, the author believes that care is necessary if the communications to members include a comparison of the market value of assets and liability cash flows discounted at the expected rate of return: this would be misleading if interpreted as a measure of the strength of the fund (Cowling et al., 2012; Cowling et al., 2017).

\section{Discussion}

Several actuarial papers have argued that it is misleading to calculate technical provisions using a budgeting framework, and for this to be the focus of communication to members: this is a criticism of current practice. The TPR (2019) figures showed that schemes, in aggregate, had assets of $90.3 \%$ of technical provisions for valuations in 2016/17 (Table 2.1b). The average outperformance of the SEDR over 20 -year gilts was 0.9 percentage points (Table 4.4). Given that a 0.5 percentage point decrease in the discount rate increases liabilities by about $10 \%$, this implies that moving to a gilt discount rate would reduce the average funding ratio to around $77 \%$. This figure would be higher when account is taken of swap rates and the IA and when bias from prudence in mortality 
and other assumptions is removed. It would be helpful to carry out research to establish how, for a range of schemes, funding ratios calculated on the suggested benchmark basis would differ from ratios currently calculated according to technical provisions. A little over a quarter of schemes discount at gilts +0.5 percentage points or less (Table $4.9 \mathrm{a}$ ), where the effect of the new basis may be quite modest. But the more significant impact arises for the quarter of schemes using a SEDR of over 1.33 percentage points above 20 -year gilt yields (Table $4.9 \mathrm{a}$ ). Schemes taking advantage of an assumed equity risk premium in determining a discount rate would not be allowed to do so. Prescription replacing discretion would, it is argued, improve transparency and understanding as well as moving from the budgeting to the matching framework.

The benchmark valuation can also be used for setting a funding target. Care is needed as the target should reflect the objectives of the parties; if the firm's aim is to target buyout (Cowling et al., 2017), then the target may be set in relation to the buyout cost. In other cases, the valuation here proposed will help meet the need for the target to relate to solvency (Chapman et al., 2001) and to do so clearly (Cowling et al, 2005). Hatchett et al. (2013) argued that a target set using market values (as is the benchmark valuation here) is helpful, by being objective, clarifying the reliance on the firm and what is the matching portfolio (from which departures may be made).

The author has put forward a basis for a new benchmark valuation. What action do regulators take? The starting point is requiring information, naturally including the solvency position at the valuation date and projected in, say 5 and 10 years' time. They also need risk disclosures; in the short term the simplest approach would be sensitivities, perhaps along the lines of the stresses used by the PPF (2019).

Regulators then have to design a process regarding when trustees and firms need to take action and what action. Head et al. (2001) suggested that trustees and members would not find it easy to accept the psychology of a target solvency ratio under $100 \%$. So, with a starting point of the current solvency ratio, the regulator would also consider how far below $100 \%$ it is; the risks being taken, risk disclosures and risk margin (excess of buyout cost over liabilities); the employer covenant; and the solvency projected for the future. The past record of managing the scheme and its governance can also be relevant. The current Code of Practice has a useful list of matters to be taken into account (TPR, 2014, para. 102).

It is useful to consider the need for the actions taken regarding pension schemes to take account of the interests of the employees more widely than accrued benefits and of the sustainable growth of the firm. Where a scheme continues to offer future accrual, salary-related increases in pensions and, possibly, is open to new entrants, employee members have an interest in the non-accrued benefits not covered by the solvency measure proposed. Further, the finances of the pension scheme may threaten the well-being (and possibly solvency) of the firm, with consequences for the level of employment and of salaries that the firm can offer. The author believes that this does not invalidate the merits of a solvency measure as proposed but emphasises that schemespecific management is needed to reflect the responsibilities of the trustees and interests which may go beyond accrued benefits. However, scheme deficits have potential consequences for the PPF, and decisions on the approach for regulators to take involve political considerations rather than some straightforward actuarial solution.

Regulators will also take a view on what information on scheme finances should be disclosed to members. Do members need any as they have protection from the PPF? But knowing the state of the scheme can be helpful as this may affect the employer's attitude to keeping the scheme open or making changes, and the potential for wage increases; and the PPF does not always pay members' entitlements in full. The benchmark valuation, based on a matching framework, can help members measure the value of pension promises as part of their remuneration bargaining (Exley et al., 1997). It would be a retrograde step to withdraw financial information from the disclosure to members.

Given that funding and investment are linked, the idea of Cowling et al. (2017) to combine the Statements of Funding Principles and Investment Principles is sensible; the author suggests a 
“Statement of Financial Management Principles", which would include the trustees' objectives for funding and their investment policy (the proposal for a statement of funding and investment strategy proposed in the Pension Schemes Bill is welcome). In particular, trustees should set out the extent to which and how they plan to depart from a matched investment strategy, and whether they are using assets of types that will not expose the scheme to risks from early encashment. It is also the opportunity to explain the desired solvency level. This could exceed $100 \%$ if the firm wished to retain in the fund a risk margin for unhedgeable risks or for high-risk investments such as equities, if it refrained from selecting assets of a type that support the IA, if it was planning for a buyout, or, less likely, funding for pensions resulting from future salary increases (since the benchmark valuation uses the current unit method).

The IORP Directive contains the options on discount rate that are replicated in current regulations but does not require that all those options are made available to schemes. Indeed, a number of different approaches are taken by countries in the EU (Patel, 2007; Cowling et al., 2017). The Directive should not, therefore, constrain the suggestions in this paper (regardless of whether the UK has to comply with the Directive). However, to assist TPR in a new Code of Practice, the author agrees with other actuarial researchers who have taken the view that the practice of disclosing a funding ratio using the budgeting approach to valuation can result in members being given a misleading impression of the financial state of their scheme.

\section{Conclusion}

This paper has argued the case for solvency valuations of DB schemes that use a market-based approach, discounting cash flows at risk-free yields. This has also been the conclusion of many other actuarial researchers over the last 25 years: a point worth stressing, as it is not current practice.

Below is a summary of other points where the author contributes to the discussion:

- The distinction between scheme-specific management and valuation assumptions set by regulation;

- The discount rate should not reflect the strength of the firm covenant;

- There is a case for an IA (which could be greater for an open scheme) but with considerable care needed;

- The use of probability-weighted expectations in calculating liabilities, rather than use of the term "best estimate";

- Scheme management should be prudent; but prudent margins should not be part of liabilities;

- Risk margins should not be part of liabilities, but the buyout cost should be disclosed as an indication of risk;

- Risk sensitivities should be disclosed, possibly along the lines of the stresses used by the PPF;

- There is merit in a reconciliation of the valuation of liabilities as here proposed with the amount needed to fund benefits on a budgeting approach using the estimated return on assets held; and

- Trustees should issue a "Statement of Financial Management Principles".

Some would say it is satisfactory to continue with the two valuations currently used:

- an "ongoing" valuation using technical provisions as presently calculated; and

- a "discontinuance" valuation as if there was an insurance buyout - relevant to determining what deficit would arise if employer support ceased (a critical risk for members). 
However, the author believes that, while technical provisions can help determine the level of future contributions to the fund:

- neither of the above two valuations tells us whether the scheme is on track to pay the promised benefits on the basis that the employer and trustees fulfil (rather than transfer) their obligations; and

- using technical provisions as the liabilities is especially unsuitable for this purpose as this takes credit for future investment returns above the risk-free rate and involves a degree of discretion that means the result is not a clear and consistent indicator of the financial strength of the fund.

The author's proposed benchmark for a solvency valuation is the suggestion he puts forward. Naturally, it will be a political decision as to what regulation results from the Pension Schemes Bill when passed and the way regulation is to be carried out. There is, though, an important role for the actuarial profession to draw the attention of regulators and politicians to the insights from the expertise of actuarial researchers and those with practical experience in this area.

The IFoA has been encouraged to influence TPR to ensure that trustees set funding objectives that are well defined and refer to solvency and to lobby for better information to be provided to members on solvency: those proposals were some 14 years ago in Cowling et al. (2005). In the discussion on that paper, Exley (2005, page 111) said

"I would be surprised and disappointed if this [solvency-based approach] is not embraced universally by the [IFoA] within the next few years, and I would urge the Pensions Board to make application of the key ideas mandatory".

The present author admits his disappointment. The objectives of solvency-related targets and member information have not been achieved, despite these being consistent with much of the actuarial literature from the late 1990s onwards. There is now an opportunity for change.

Acknowledgements. The author would like to thank David Bartlett, Charles Cowling and Paul Fulcher for valuable comments on a draft of the paper. The comments of anonymous reviewers are also much appreciated.

Disclaimer. The views expressed in this publication are those of invited contributors and not necessarily those of the Institute and Faculty of Actuaries. The Institute and Faculty of Actuaries do not endorse any of the views stated nor any claims or representations made in this publication and accept no responsibility or liability to any person for loss or damage suffered as a consequence of their placing reliance upon any view, claim or representation made in this publication. The information and expressions of opinion contained in this publication are not intended to be a comprehensive study nor to provide actuarial advice or advice of any nature and should not be treated as a substitute for specific advice concerning individual situations. On no account may any part of this publication be reproduced without the written permission of the Institute and Faculty of Actuaries.

\section{References}

Arthur, T.G. \& Randall, P.A. (1990). Actuaries, pension funds and investment. Journal of the Institute of Actuaries, 117, 1-27.

Billings, M., O’Brien, C.D., Woods, M. \& Vencappa, D. (2017). Discretion in accounting for pensions under IAS 19: using the 'magic telescope'? Accounting \& Business Research, 47, 123-143.

Browne, S., Milevsky, M.A. \& Salisbury, T.S. (2003). Asset allocation and the liquidity premium for illiquid annuities. Journal of Risk and Insurance, 70, 509-526.

Chapman, R.J., Gordon, T.J. \& Speed, C.A. (2001). Pensions, funding and risk. British Actuarial Journal, 7, 605-662.

Charmaille, J.-P., Clarke, M.G., Harding, J., Hildebrand, C., Mckinlay, I.W., Rice, S.R. \& Reynolds, P. (2013). Financial management of the UK Pension Protection Fund. British Actuarial Journal, 18, 345-393.

Clacher, I. \& Moizer, P. (2011). Accounting for Pensions. Report for the National Association of Pension Funds. Leeds, Leeds University Business School. 
Cowling, C.A., Gordon, T.J. \& Speed, C.A. (2005). Funding defined benefit pension schemes. British Actuarial Journal, 11, 63-97.

Cowling, C.A., Frankland, R., Halls, R.T.G., Kemp, M.H.D., Loseby, R.L., Orr, J.B. \& Smith, A.D. (2012). Developing a framework for the use of discount rates in actuarial work. British Actuarial Journal, 17, 153-211.

Cowling, C.A., Fisher, H.J., Powe, K.J., Sheth, J.P. \& Wright, M.W. (2017). Funding of defined benefit pension schemes: an integrated risk management approach, British Actuarial Journal, 24, e7, 1-69.

Day, J.G. \& McKelvey, J.M. (1964). The treatment of assets in the actuarial value of a pension fund. Journal of the Institute of Actuaries, 90, 104-147.

Department of Work and Pensions (2017). Security and sustainability in defined benefit pension schemes. Cm 9412 .

Department of Work and Pensions (2018a). Consolidation of defined benefit pension schemes. Consultation.

Department of Work and Pensions (2018b). Protecting defined benefit pension schemes - a stronger pensions regulator. Consultation.

Dodds, L.S. (2018). An open mind. Pensions Age, March.

Dullaway, D. (2009). Financial crisis: liquid assets? The Actuary (online), January.

Duval, D. (2019). Actuarial methods: are we serving the public interest? British Actuarial Journal, 24, e15, 4-6.

Dyson, A.C.L. \& Exley, C.J. (1995). Pension fund valuation and investment. British Actuarial Journal, 1, 471-540.

EFRAG (2008). The financial reporting of pensions: discussion paper, available at https://www.efrag.org/Assets/Download? assetUrl=\%2Fsites\%2Fwebpublishing\%2FProject\%20Documents\%2F70\%2FDP\%20-\%20Pension\%20Accounting.pdf

EFRAG (2009). The financial reporting of pensions: feedback and redeliberations, available at https://www.efrag.org/Assets/ Download?assetUrl=\%2Fsites\%2Fwebpublishing\%2FProject\%20Documents\%2F70\%2FPAAinE\%20The\%20Financial\%20 Reporting\%20of\%20Pensions\%20-\%20Feedback\%20and\%20Redeliberations\%20Report.pdf

Exley, C.J. (2002). The Trouble with FRS17, The Actuary, available at https://www.theactuary.com/archive/old-articles/part-5/ the-trouble-with-frs17/

Exley, C.J. (2005). Comment in discussion of Cowling, Gordon \& Speed (2005). British Actuarial Journal, $11,111$.

Exley, C.J., Mehta, S. \& Smith, A.D. (1997). The financial theory of defined benefit pension schemes. British Actuarial Journal, 3, 835-938.

Foroughi, K. (2012). Market-consistent values and Solvency II: implications of the recent financial crisis. British Actuarial Journal, 17, 18-65.

Gilley, D.F. (1972). The dissolution of a pension fund. Journal of the Institute of Actuaries, 98, 179-215.

Government Actuary's Department (2018). Investment News, December.

Hatchett, J., Hurd, M. \& Clacher, I. (2013). Meeting defined benefit obligations: measurement, risk and flight paths. British Actuarial Journal, 18, 271-307.

Head, S.J., Adkins, D.R., Cairns, A.J.G., Corvesor, A.J., Cule, D.O., Exley, C.J., Johnson, I.S., Spain, J.G. \& Wise, A.J. (2000). Pension Fund Valuations and Market Values. British Actuarial Journal, 6, 55-118.

Head, S.J., Adkins, D.R., Cairns, A.J.G., Corvesor, A.J., Cule, D.O., Exley, C.J., Johnson, I.S., Spain, J.G. \& Wise, A.J. (2001). Pension Fund Valuations and Market Values: survey of practice. British Actuarial Journal, 7, $103-122$.

Hue, B., Junks, A., Spain, J., Bora, M. \& Siew, S. (2019). Investment risk for long-term investors: risk measurement approaches. British Actuarial Journal, 24, e16, 1-52.

Institute and Faculty of Actuaries (2012). A framework for the use of discount rates in actuarial work.

International Actuarial Association (2018). Risk Adjustments for Insurance Contracts Under IFRS 17.

International Accounting Standards Board (2018). Conceptual Framework For Financial Reporting. Delaware, IFRS Foundation.

Keating, C., Hatchett, J., Smith, A., Walton, J. \& Zhao, T. (2016). Liquidity: essence, risk, institutions, markets and regulation: a report of the liquidity working party. British Actuarial Journal, 21, 5-74.

Mariathasan, M. \& Merrouche, O. (2014). The manipulation of Basel risk-weights. Journal of Financial Intermediation, 23, 300-321.

McAleer, J. \& Wardle, G. (2018). When cash becomes king. The Actuary, November, 16-17.

McLeish, D.J.D. \& Stewart, C. M. (1987). Objectives and methods of funding defined benefit pension schemes, Journal of the Institute of Actuaries, 114, 155-225.

Myners, P. (2001). Institutional Investment in the UK. London, HM Treasury.

Napier, C.J. (2009). The logic of pension accounting. Accounting and Business Research, 39(3), 231-249.

Patel, C. (2007). Minimum Technical Provisions for Occupational Pensions in the EU. A Summary of Minimum Funding Requirements. Groupe Consultatif Actuariel Europeen.

Patel, C. \& Daykin, C.D. (2010). Actuaries and Discount Rates, A Discussion Paper. Institute \& Faculty of Actuaries.

Pension Protection Fund (2019). Commercial consolidator appendix, available at https://www.ppf.co.uk/sites/default/files/ file-2019-12/commercial_consolidator_appendix_2021.pdf

Pension Protection Fund and The Pensions Regulator (2016). Written evidence to the Work and Pensions Committee inquiry, available at http://data.parliament.uk/writtenevidence/committeeevidence.svc/evidencedocument/work-and-pensionscommittee/pension-protection-fund-and-the-pensions-regulator/written/39219.html 
Pension Schemes Bill (2020). Available at https://publications.parliament.uk/pa/bills/lbill/58-01/004/5801004.pdf (downloaded 23 January 2020).

The Pensions Regulator (2014). Funding defined benefits. Regulatory code of practice 03.

The Pensions Regulator (2018). Annual funding statement for defined benefit schemes.

The Pensions Regulator (2019). Scheme funding statistics: annex.

Ralfe, J. et al. (2018). Letter dated 12 October 2018 to Mr Bill Galvin, Group Chief Executive Officer USS Limited, 'Report of the joint expert panel on USS September 2018', available at www.johnralfe.com

Rule, D. (2018). An annuity is a very serious business. Speech at Westminster and City conference, available at https://www. bankofengland.co.uk/-/media/boe/files/speech/2018/an-annuity-is-a-very-serious-business-speech-by-david-rule

Salt, H. (2019). Actuarial methods: are we serving the public interest? British Actuarial Journal, 24, e15, 1-4.

Telford, P.G., Browne, B.A., Collinge, E.J., Fulcher, P., Johnson, B.E., Little, W., Lu, J.L.C., Nurse, J.M., Smith, D.W. \& Zhang, F. (2011). Developments in the management of annuity business. British Actuarial Journal, 16, 471-551.

Turnbull, C. (2017). A History of British Actuarial Thought. Cham, Switzerland, Palgrave Macmillan.

Cite this article: O’Brien CD. (2020). Actuarial valuations to monitor defined benefit pension funding. British Actuarial Journal. https://doi.org/10.1017/S1357321720000173 